\title{
Editorial
}

Joachim Wagner*

\section{Econometric Studies with Integrated Micro-data from German Official Statistics}

https://doi.org/10.1515/jbnst-2018-5001

This special issue contains revised versions of three papers presented at a workshop in Berlin in March 2017 where research projects were discussed that are based on different sets of integrated micro-data from German official statistics.

The first two papers look at the effects of two different types of subsidies. Matthias Brachert, Eva Dettmann and Mirko Titze investigate the links between public investment subsidies from the regional policy scheme „Improving Regional Economic Structures“ granted to firms in East Germany and various dimensions of firm performance. Among others, they find positive effects on firm employment.

Solveigh Hennig and Gunnar Breustedt examine the impact of agricultural subsidies on rental rates for grassland between 2001 and 2013. One important result points to an almost complete capitalization of funding into the rental price of grassland at the end of the period under investigation.

The last paper by Joachim Wagner uses merged information from foreign trade transactions and from surveys by official statistics to demonstrate that the number of foreign markets a firm is active on is higher in firms that are larger, older and foreign owned and that have higher labor productivity, human capital intensity and R\&D intensity.

The papers in this special issue illustrate that micro-data from German official statistics that are combined with micro-data from different sources are a powerful tool to investigate policy-relevant topics and can be helpful to inform evidence-based policy. For comprehensive descriptions of available integrated longitudinal micro-data from official statistics in Germany see www.forschungs datenzentrum.de/afid.asp.

*Corresponding author: Joachim Wagner, Leuphana University Lueneburg, D-21314 Lueneburg, Germany; and CESIS, KTH, Stockholm, Sweden, E-mail: wagner@leuphana.de 